\title{
Optimization of mechanical crimping to assemble tubular components
}

\author{
Manas Shirgaokar ${ }^{\mathrm{a}}$, Hyunjoong Cho ${ }^{\mathrm{a}}$, Gracious Ngaile ${ }^{\mathrm{a}}$, Taylan Altan ${ }^{\mathrm{a}, *}$, \\ Jang-Horng Yu ${ }^{b}$, John Balconi ${ }^{b}$, Richard Rentfrow ${ }^{b}$, W.J. Worrell ${ }^{\mathrm{b}}$ \\ ${ }^{a}$ ERC for Net Shape Manufacturing, The Ohio State University, 339 Baker Systems, 1971 Neil Avenue, Columbus, OH 43210, USA \\ b Science and Technology Group, Alliant Ammunition and Powder Company, Radford Army Ammunition Plant, \\ Route 114, P.O. Box 1, Radford, VA 24141-0096, USA
}

\begin{abstract}
The crimping process is used often in the assembly of tubular components. In this study, with the aid of the finite-element method (FEM), the mechanical crimping operation was evaluated and optimized for a specific application. The effect of various process variables, such as the geometry, alignment and stroke of the crimper and the friction at the crimper-tube interface were investigated. Thus, it was possible to optimize the process so that the effect of springback could be reduced and the assembly quality, as indicated by the pullout force, could be improved. The crimping process of a single-grooved rod with a tube was evaluated as a case study. Based on the FE simulations, it was possible to determine the optimum alignment and the optimum design for two types of crimper geometries.
\end{abstract}

(c) 2003 Elsevier B.V. All rights reserved.

Keywords: Assembly; Crimping; Pullout test; FEM

\section{Introduction}

Traditional joining methods use resistance spot-welding or fastening elements such as screws, pegs, rivets, bolts and nuts. Though screws, clamps and rivets are very commonly used, these can be costly and not very reliable over long periods of time [1]. Thus, there has been a growing interest in fastening processes which do not require additional joining elements and which can be combined with adhesive joining techniques to yield reliable and inexpensive assemblies. This has resulted in considerable research work on assembly processes such as clinching, hemming and crimping. The main advantage of such processes is that they do not require any pre- or post-processing, since there is no heat or thermal distortion involved [1]. Thus, pre-painted components can be used for the assembly operation. Another advantage is the absence of chips, dirt or fumes, which provides a safe and hazard-free work environment. Traditionally the design of clinching and crimping operations has relied on experience and costly trial-and-error experiments. This paper discusses the application of finite-element method (FEM) in evaluation of a mechanical crimping process in order to enhance the performance of the assembly by determining the optimum process and geometrical parameters. A case study of

\footnotetext{
* Corresponding author.

E-mail address: altan.1@osu.edu (T. Altan).

URL: http://www.ercnsm.org.
}

the crimping process used in manufacturing bullets is presented.

In the present study, the bullet is considered as a cylindrical solid rod that must be assembled to the casing, which is essentially a tubular part with a specific geometry and material. Thus, during crimping, the bullet is lowered into a tubular casing to a predetermined depth, and then six segmented crimpers/dies are pushed into the tube/casing by hydraulic rams, forming the crimp (Fig. 1 ). The tube is deformed to fill a groove, which is machined on the solid cylinder. The crimp quality, which is critical to the final performance of the assembly, is evaluated by a test, which measures the force that is required to pull the rod from the tube, the so-called "pullout test". A variation in the geometrical properties of the crimp will cause variations in the strength and quality of the assembly that must satisfy certain specifications. During the pullout test, the tube rarely ruptures. However, when it does, the damage is normally near the crimp. Thus, the quality of the crimp is extremely important because it determines the quality of the assembly. A ruptured tube or an excessive amount of crimping would affect the function of the assembly, which can result in excessive scrap and costs. Another application of the crimping operation is in the field of electrical engineering for assembling composite insulators, which are fast, replacing porcelain ones in electrical applications. These insulators consist of a glass-reinforced polymer (GRP) rod with two metal end fittings, which are radially crimped onto it [2]. This process 


\begin{tabular}{|ll|}
\hline \multicolumn{2}{|l|}{ Nomenclature } \\
$E$ & Young's modulus \\
$E_{\mathrm{r}}$ & reduced Young's modulus \\
$h$ & crimper alignment \\
$H$ & height of the crimp head \\
$H_{\mathrm{b}}$ & Brinell hardness \\
$K$ & material strength coefficient \\
$L$ & length of the flat nose crimp head \\
$n$ & strain hardening coefficient \\
$R$ & crimper nose radius \\
$s$ & crimper/tool stroke \\
& \\
$G r e e k$ & letters \\
$\theta$ & crimp head included angle \\
$\mu$ & crimper-tube interface friction \\
$\nu$ & Poisson's ratio \\
$\bar{\sigma}, \bar{\varepsilon}$ & effective stress and effective strain \\
\hline
\end{tabular}

is similar to the bullet crimping case study discussed in this paper.

The principal objectives of the study were to determine:

(a) The optimum alignment of the tool/crimper with respect to the groove in the stock/rod (Fig. 2). The variation of this alignment influences the pullout force.

(b) The optimum tool/crimper geometry (Fig. 2). The optimum design is defined as one that gives maximum pullout force with minimum thinning of the tube wall.

The crimping process used for the present assembly application could be considered as a hybrid process, since a sealant is used during crimping. This sealant is somewhat similar to an adhesive and is applied over the groove in the rod. Thus, the sealant affects the interface friction condi-

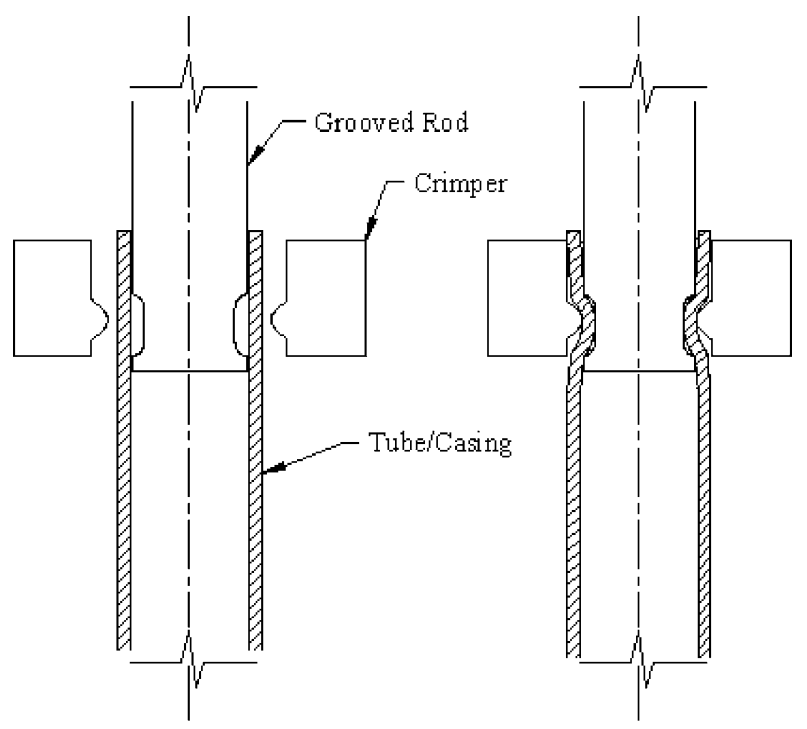

(a) Before crimping

(b) After crimping tions during crimping and pullout. Since it was not possible to model the sealant in the FE code used for this study, this effect was considered by using different coefficients of friction $(\mu)$ during crimping and pullout.

\section{Material properties of the tube/casing}

Processes involved in forming the tube (casing) consist of cold forming operations (extrusion, drawing, sizing, and so on), stress relieving, and heat treatment. During each stage, changes in the mechanical properties of the tube material such as yield stress and hardness occur. Hence the flow stress of the original tube material cannot be used directly as an input to the simulations. Thus, it was necessary to determine the modified flow stress curve of the tube material prior to crimping.

The tube used in the present application is extruded from steel. It is then heat treated and annealed to meet certain hardness requirements, which were specified for the required application. It was not possible to trace the history of all the steps that affected the hardening properties of the tube prior to the crimping operation. Thus, the hardness distribution in the crimped region was used to find a stress-strain curve for the tube material in the vicinity of the crimping area. The following relationship between the flow stress and hardness was used [3]:

$\bar{\sigma}=E_{\mathrm{r}}\left(\frac{H_{\mathrm{b}}}{1.7 E_{\mathrm{r}}}\right)^{1 / 0.92}$

where $E_{\mathrm{r}}$ is the reduced Young's modulus defined as $E_{\mathrm{r}}=$ $E /\left(1-v^{2}\right), \bar{\sigma}$ the flow stress defined as $\bar{\sigma}=K \bar{\varepsilon}^{n}$, and $H_{\mathrm{b}}$ the hardness (ksi). This equation is valid when $H_{\mathrm{b}} / E_{\mathrm{r}}$ is less than 0.16 and can describe the relation between flow stress and hardness better than using a simple linear relation [4].

For elastic material data, Young's modulus, E, and Poisson's ratio, $v$, for the tube material (steel) were chosen as follows:

$$
E=206.842 \mathrm{GPa}(30000 \mathrm{ksi}) \text { and } \quad v=0.3
$$

For the description of plastic behavior of the tube material, a tensile stress-strain curve from steel in the annealed condition $\left(\bar{\sigma}=130.8 \bar{\varepsilon}^{0.17} \mathrm{ksi}=901.834 \bar{\varepsilon}^{0.17} \mathrm{MPa}\right)$ was used. However, the origin of this curve was shifted by an amount of pre-strain (Fig. 3) calculated in the following way [5,6]. First, for each given hardness number on the upper part of the tube (crimping region), an equivalent flow stress value was calculated by using Eq. (1), which correlates the flow stress and the hardness.

By rewriting Eq. (1) in terms of hardness and the reduced Young's modulus, an equivalent flow stress value was calculated:

$$
\bar{\sigma}=E_{\mathrm{r}}\left(\frac{H_{\mathrm{b}}}{1.7 E_{\mathrm{r}}}\right)^{1 / 0.92}=669.205 \mathrm{MPa}(97.06 \mathrm{ksi})
$$

Fig. 1. Components before and after the crimping operation. 


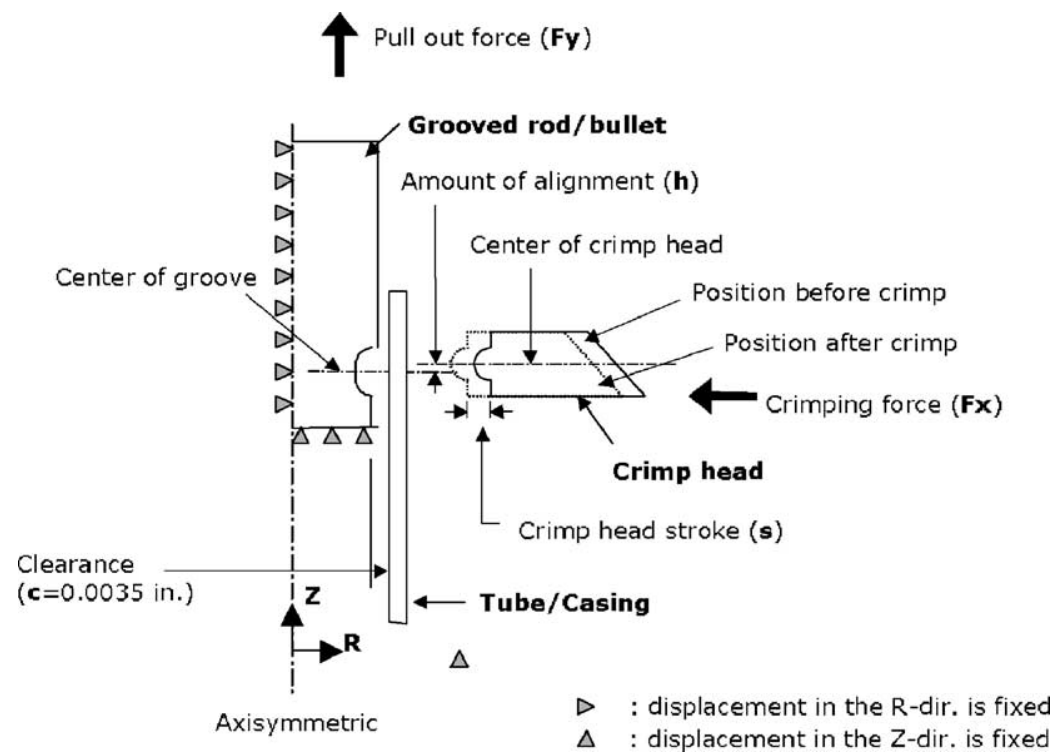

Fig. 2. Alignment of the tool with respect to the groove in the rod.

where $H_{\mathrm{b}}=263 \mathrm{ksi}=1813.32 \mathrm{MPa}$ and reduced Young's modulus $=E_{\mathrm{r}}=E /\left(1-v^{2}\right)$. The corresponding plastic strain was found from the tensile stress-strain curve from the annealed steel, i.e. $\bar{\sigma}=130.8 \bar{\varepsilon}^{0.17} \mathrm{ksi}$ :

$\varepsilon_{\text {equiv. }}=\exp \left[\frac{\ln \bar{\sigma}-\ln K}{n}\right]=0.173$

The elastic strain limit (i.e. strain at yielding) was calculated with $0.2 \%$ strain offset limit and the slope of the stress-strain curve in the elastic region.

$\varepsilon_{\text {yield }}=\varepsilon_{0.2 \%}+\frac{\sigma_{\mathrm{Y}}}{E}=0.002+\frac{97.06}{30000}=0.003$

Then, the original stress-strain curve was shifted by the amount of the difference between the equivalent plastic strain and elastic strain limit (Fig. 3):

$\Delta \varepsilon=\varepsilon_{\text {equiv. }}-\varepsilon_{\text {yield }}=0.173-0.003=0.17$

Finally, the shifted curve (Fig. 4) had a new yield stress and a new slope of work hardening, which could approximately describe the behavior of plastic deformation in the upper part of the tube during the crimping process.

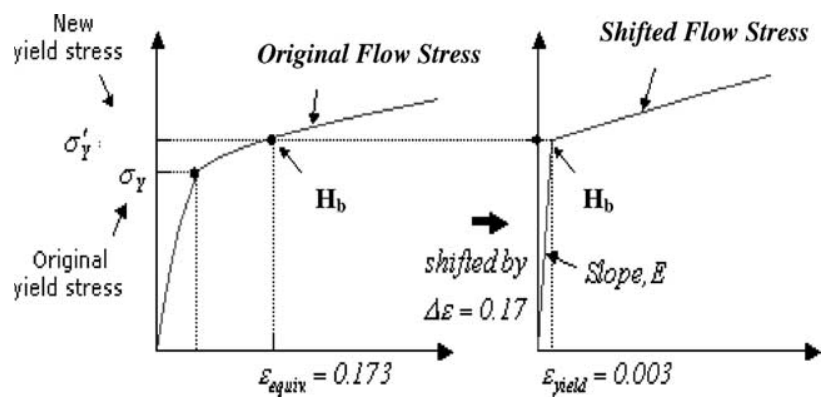

Fig. 3. Concept of flow stress curve shifting.

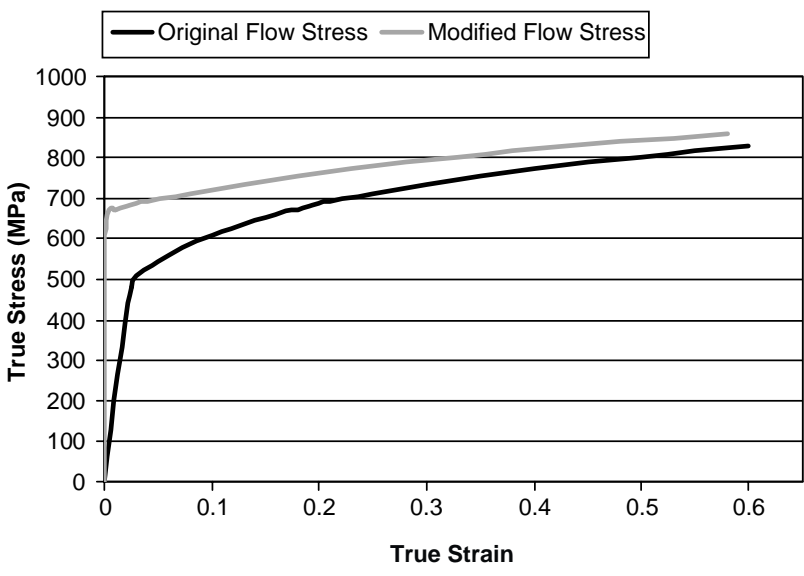

Fig. 4. Shifted flow stress curve for the upper part of the tube.

\section{Determination of optimum crimper alignment}

The optimum alignment between the crimper and the groove (in the stock/rod) was defined as one, which gave maximum pullout force with minimum straining and thinning of the tube [7].

With the aid of FEM, a parametric study of the crimping operation was conducted to identify the factors that affect the thinning distribution and the pullout force. These factors were identified as the alignment between the crimper and the groove (in the stock/rod), the tool stroke and the coefficient of friction at the crimper-tube and rod-tube interfaces [7]. Simulations were carried out for the crimping process, followed by the springback and the rod/bullet pullout test. The parameters used in the simulations are discussed below:

(a) Crimper alignment $(h)$

The crimper geometry and the alignment $(h)$ are seen in Fig. 2. To properly evaluate the effects of the tool 
alignment on the pullout force, it was decided to study six alignments (e.g. $-0.4445 \mathrm{~mm}, 0.000$ (reference line), $+0.254,+0.381,+0.4445$ and $+0.508 \mathrm{~mm})$.

(b) Tool stroke $(s)$

The crimping operation was simulated for two tool strokes of $1.016 \mathrm{~mm}(0.04 \mathrm{in}$.) and $0.953 \mathrm{~mm}(0.038 \mathrm{in}$.) to observe the influence of the tool stroke on thinning distribution and consequently the pullout force (Fig. 2). The change in the percentage thinning when the stroke is increased from 0.953 to $1.016 \mathrm{~mm}$ was investigated. Excessive thinning may result in damage to the tube and subsequently failure of the assembly during final quality assurance test or during final use.

(c) Tool and tube interface friction $(\mu)$

For the crimping process and the springback, a coefficient of friction $(\mu)$ of 0.08 was assumed whereas for the pullout simulations two values of friction were considered, $\mu=0.2$ and 0.3. A lower coefficient of friction was used for the crimping and springback simulations because these operations are carried out in the presence of a lubricant whereas the pullout test is done under dry conditions, resulting in a metal-to-metal contact and hence larger friction.

\subsection{FE simulation of crimping and springback}

FEM was used to simulate the crimping, springback and the rod pullout test with different crimper geometries. The simulations were carried out using a commercial FEM code DEFORM. Due to the geometry of the rod-tube assembly, an axisymmetric analysis was carried out, i.e. only half of the cross-section was considered for simulations (Fig. 5).

The crimping process can be regarded as a sheet metal bending process where a certain amount of springback occurs due to elastic recovery during unloading. Thus,

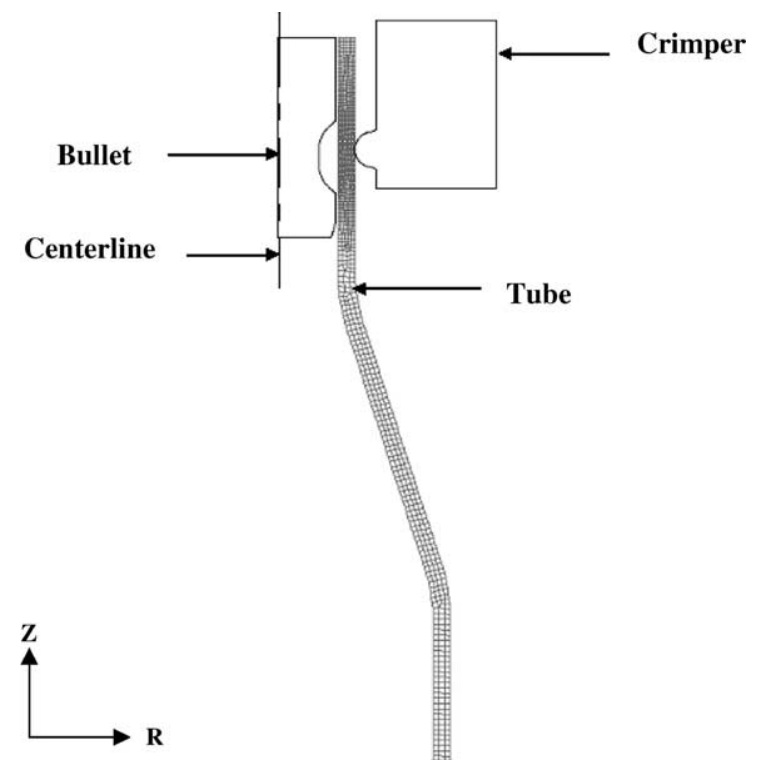

Fig. 5. FE model used for crimping. elasto-plastic analyses of the crimping process were conducted in two steps:

(a) pushing the tube/casing material into the groove in the rod/bullet using the crimp head;

(b) estimation of springback after retracting the crimp head [7].

For the crimping simulation, movement of the crimp head was achieved by prescribing negative velocity in the $R$ direction and for the springback simulation, the direction of the velocity was changed to the positive $R$ direction (Fig. 2). Since the flow stress of the tube material is a function of strain only, the magnitude of the crimp head velocity does not affect the deformation behavior or the crimping force calculation [8].

For determination of optimum alignment between the crimper and the groove in the rod, simulations were carried out for the six alignments mentioned earlier. A single simulation of the crimping process, with a tool stroke of $1.016 \mathrm{~mm}(0.04 \mathrm{in}$.) was sufficient, as the data for the tool stroke of $0.953 \mathrm{~mm}(0.038 \mathrm{in}$.) could be obtained from the results of this simulation.

The springback or unloading process was simulated after the crimping process. The springback was simulated separately for each of the two tool strokes considered, i.e. 0.953 and $1.016 \mathrm{~mm}$.

Since the springback occurs immediately after the crimping process, while the crimpers are retracted, the same coefficient of friction of $\mu=0.08$ was used in the springback simulation as in the crimping process.

\subsection{FE simulation of the pullout test}

During the simulation of springback, the crimper loses contact with the tube/casing wall while it is being retracted. This step was used to simulate the pullout test. As in the springback simulations, the strain history got carried forward into the pullout test simulations. The pullout test was simulated by removing the crimper and applying velocity to the rod/bullet in the positive $Z$ direction (Fig. 2). Since the pullout test is carried out under dry conditions, a higher coefficient of friction is required. Thus, frictional values of $\mu=0.2$ and 0.3 were used to simulate the pullout test for each of the alignments considered.

\subsection{Optimum crimper alignment}

The results of the thinning distribution and the pullout force were obtained and optimized to reach the value of alignment that could be considered as best suited for the purpose. The pullout force influences the shot start pressure in the tube at the time of firing and thus affects important parameters of the ballistic performance, viz. muzzle velocity, accuracy, etc. Excessive thinning not only reduces the pullout force but also increases the tendency of failure during the final quality testing of the bullet. A compromise between 


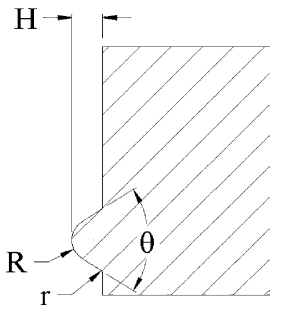

Fig. 6. Crimper with a round nose.

the values of the pullout force and thinning distribution is inevitable. The optimum alignment for a round-nosed crimper with crimp head angle $\theta$ and nose radius $R$ was determined (Fig. 6). Due to the proprietary aspects of this study, the actual dimensions of the crimper are not given here.

\subsubsection{Thinning distribution}

The thickness of the tube/casing over the region of crimping were obtained from the FEM code DEFORM after the simulation of crimping and springback. The resulting thinning and the increase in thinning with increase in the stroke were noted in each case.

A parabolic profile of the thinning distribution was observed (Fig. 7). Maximum thinning was observed when the crimper was aligned $0.508 \mathrm{~mm}$ above the centerline of the groove in the rod/bullet for both the tool strokes. When the tool stroke was $0.953 \mathrm{~mm}$, minimum thinning was observed for the alignments $h=0,0.254$ and $0.381 \mathrm{~mm}$.

\subsubsection{Optimum alignment for tool stroke $=0.953 \mathrm{~mm}$ (0.038 in.)}

The results of the pullout simulations carried out for the different alignments with a tool stroke of $0.953 \mathrm{~mm}$ were combined with the thinning distribution obtained for this stroke (Fig. 8) to determine the optimum range of alignment for the crimping process.

Fig. 8 shows the pullout force and the thinning distribution against the six alignments, at $\mu=0.2$ and 0.3 . It was observed that the graph of thinning distribution reached a minimum value at alignments of $h=0.381$ and $0.254 \mathrm{~mm}$ and at the centerline $(h=0 \mathrm{~mm})$. The point, which gave maximum pullout force with minimum thinning, was considered to be the optimum condition. Thus, the position of the crimper at the centerline was found to be optimum. The pullout force was found to be $25.46 \mathrm{kN}(5.725 \mathrm{klbf})$ for a tool stroke of $0.953 \mathrm{~mm}$ and $\mu=0.2$. When the friction coefficient $\mu=0.3$, the optimum value of alignment remained the same though the pullout force increased to $26.86 \mathrm{kN}$ (6.04 klbf) (Fig. 8).

\subsubsection{Optimum alignment for tool stroke $=1.016 \mathrm{~mm}$ (0.04 in.)}

The same procedure, as in the previous case of stroke of $0.9525 \mathrm{~mm}(0.0375 \mathrm{in}$.), was followed to obtain the optimum alignment for a stroke of $1.016 \mathrm{~mm}(0.04 \mathrm{in}$.). For $\mu=0.2$, an optimum alignment of $0.254 \mathrm{~mm}$ above the centerline was observed (Fig. 9) which gave a pullout force of $25.61 \mathrm{kN}$ (5.759 klbf) for a tool stroke of $1.016 \mathrm{~mm}$. For $\mu=$ 0.3 , though the optimum alignment remained the same, the force achieved during pullout increased to $26 \mathrm{kN}$ (5.847 klbf) (Fig. 9).

Figs. 8 and 9 give the optimum values of crimper alignment for the coefficients of friction of 0.2 or 0.3 . However, it is possible to estimate the pullout force per alignment by interpolating or extrapolating between the present values of the coefficients of friction and for the values thought to be more appropriate for the process. For a tool stroke of $0.953 \mathrm{~mm}$ (Fig. 8), there was a region on the graph where the thinning remained at a minimum level of $6.06 \%$. This gave a wider choice of pullout forces to choose from.

If a certain amount of thinning is allowed in the crimping process, the corresponding value of the pullout force that can be achieved is available (Figs. 8 and 9). Conversely, if one has a certain pullout force as a design constraint in the optimization process, then the corresponding
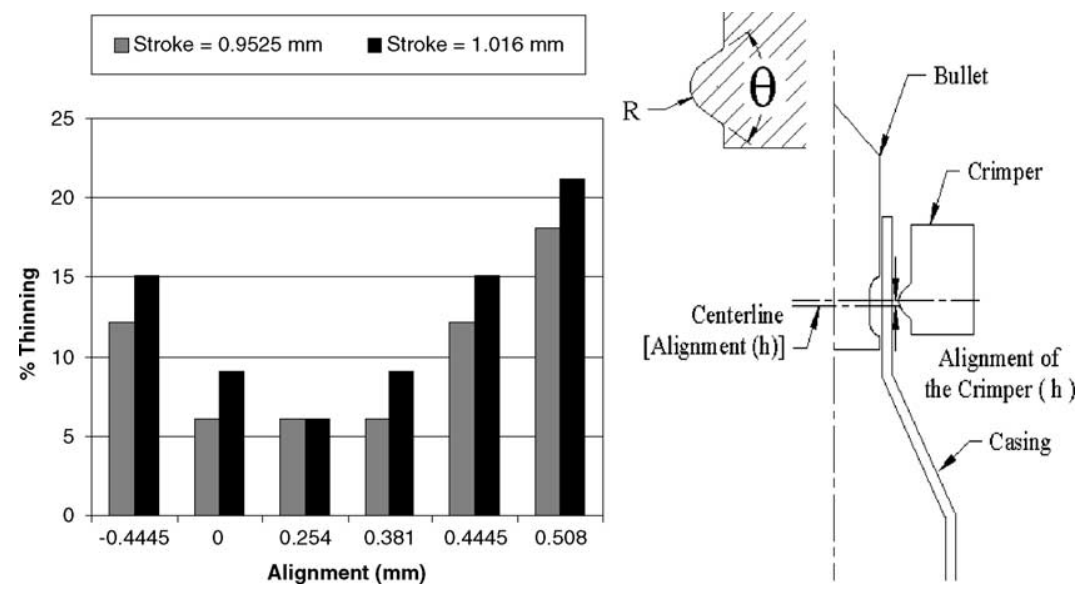

Fig. 7. Bar graph of percent thinning vs. the alignment of the crimper with respect to the centerline of the groove in the rod (bullet). 


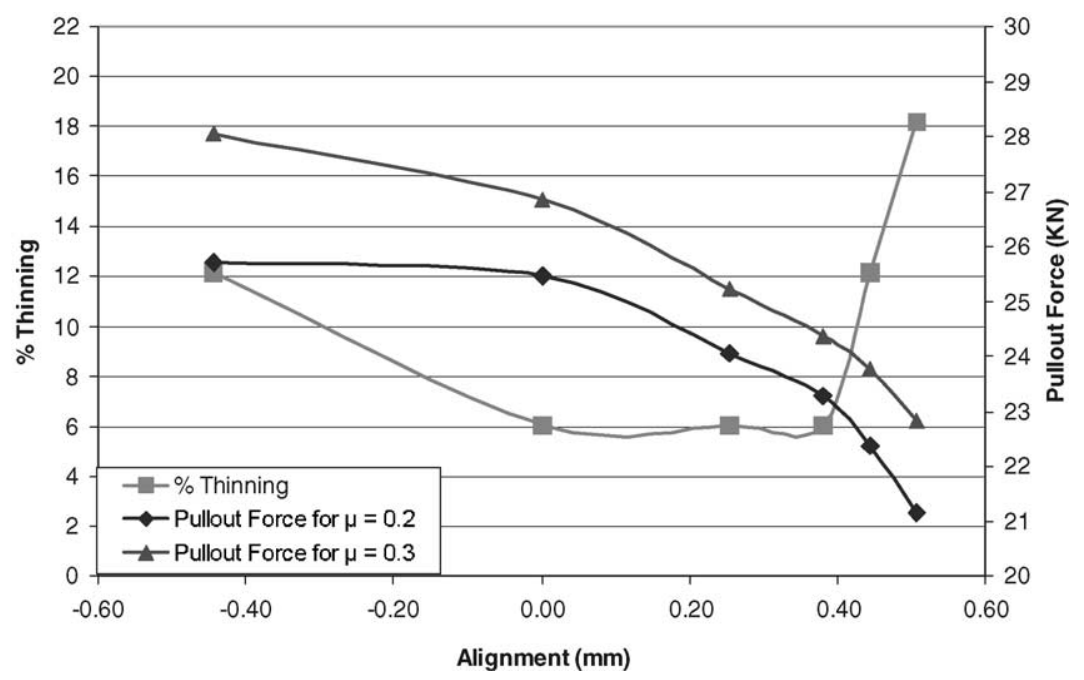

Fig. 8. Variation of pullout force and percent wall thinning for different alignments of the crimper tool for a stroke of $0.953 \mathrm{~mm}(0.038 \mathrm{in}$.).

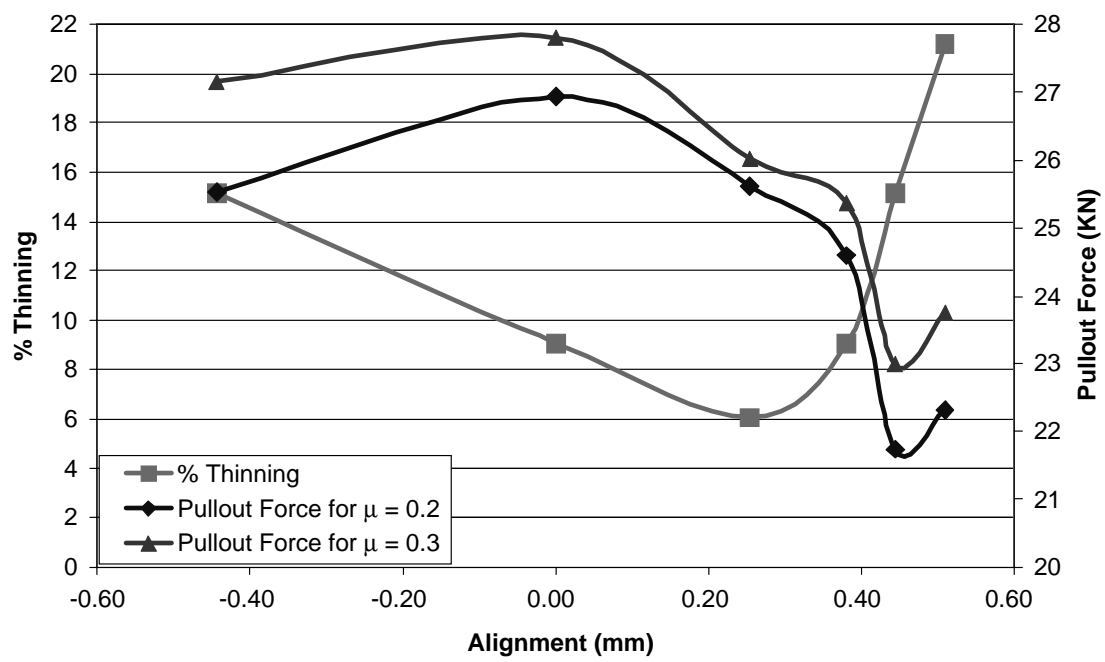

Fig. 9. Variation of pullout force and percent wall thinning for different alignments of the crimper tool for a stroke of $1.016 \mathrm{~mm}(0.04 \mathrm{in}$.).

thinning could be obtained to decide whether it is acceptable.

\section{Evaluation of alternative die designs}

Alternative die/crimper designs were evaluated based upon the results obtained from the determination of the optimum alignment of the crimper with respect to the groove in the rod (bullet).

A parametric study of the crimping operation was conducted to determine the optimum crimp head geometry. The optimum geometry was defined as one that gives maximum pullout force with minimum thinning for the process conditions selected [8]. The process parameters used for this study were the same as those used for the study of optimum crimper alignment, i.e. the crimper alignment, the tool stroke and the friction between the rod-tube and crimper-tube interfaces. Two types of crimp head geometries were considered for this study.

\subsection{Geometry I-round-nosed crimpers}

This geometry involved variants of a round-nosed crimper geometry, i.e. a crimp head with a round nose (Table 1). The parameters varied in this geometry were the crimp head angle $(\theta)$ and the nose radius $(R)$. Five variants of this geometry

Table 1

Crimper design with a round nose

\begin{tabular}{|c|c|c|}
\hline Geometry I & End radius $(R)$ & Included angle $(\theta)$ \\
\hline & $R_{1}$ & $\theta_{1}$ \\
\hline & $R_{2}$ & $\theta_{2}$ \\
\hline & $R_{3}$ & $\theta_{3}$ \\
\hline & $R_{4}$ & $\theta_{4}$ \\
\hline & $R_{5}$ & $\theta_{5}$ \\
\hline
\end{tabular}


Table 2

Crimpers with a flat nose

\begin{tabular}{|c|c|c|}
\hline Geometry II & Flat nose $(L)$ & Included angle $(\theta)$ \\
\hline & $L_{1}$ & $\theta_{1}$ \\
\hline & $L_{2}$ & $\theta_{2}$ \\
\hline & $L_{3}$ & $\theta_{3}$ \\
\hline & $L_{4}$ & $\theta_{4}$ \\
\hline
\end{tabular}

were obtained by varying the angle and keeping the height of the crimp head $(H)$ constant. Due to proprietary reasons, the actual dimensions of the nose radius $(R)$ and the crimp head angle $(\theta)$ are not disclosed in this study.

The pullout force for each of these crimpers was calculated by running simulations for two alignments and these values were then compared to determine the optimum design.

\subsection{Geometry II-flat-nosed crimpers}

This geometry has a flat nose (Table 2). Four variations of this geometry were considered (Table 2) and the pullout force was obtained from simulations conducted for two alignments. The crimp head height $(H)$ and angle $(\theta)$ were maintained constant. Due to proprietary reasons, the actual dimensions of the flat nose $(L)$ and the crimp head angle $(\theta)$ are not disclosed in this study.

\subsection{Optimum design for the round-nosed crimper}

Five variants of the round-nosed crimper design were considered (Table 1). These designs were compared on the basis of the thinning distribution and the pullout forces. To determine the optimum crimper design, the results of the FE simulations of the pullout tests for the two coefficients of friction ( $\mu=0.2$ and 0.3 ) were plotted with the thinning distribution results for each tool stroke. The optimum crimper alignment was found to range between the centerline ( $h=$ 0 ) of the groove in the bullet to $h=0.381 \mathrm{~mm}$ ( $0.015 \mathrm{in}$.) above the centerline. Only the results for an alignment of $h=0.381 \mathrm{~mm}$ are discussed here.

When the different variants of geometry I (round-nosed crimper geometry) were compared at the alignment of $h=0.381 \mathrm{~mm}$ (0.015 in.) for a tool stroke of $0.953 \mathrm{~mm}$ (0.038 in.), the designs with crimp head angles $\theta_{2}$ and $\theta_{3}$ gave more or less the same maximum pullout force at friction coefficient of 0.2 with minimum thinning of $6.06 \%$. For a coefficient of friction of 0.3 , the design with crimp head angle $\theta_{2}$ was found to be optimum (Fig. 10).

For a tool stroke of $1.016 \mathrm{~mm}(0.04 \mathrm{in}$.), the design with crimp head angle $\theta_{2}$ gave the maximum pullout force for both the coefficients of friction. However, the crimpers with crimp head angles $\theta_{1}$ and $\theta_{3}$ could also be considered for the optimization of the crimping process since they gave minimum thinning while giving a considerable pullout force. The design with included angle $\theta_{5}$ gave a high pullout force but also resulted in very high thinning of the tube at the crimped region (Fig. 11).

\subsection{Optimum design for the flat-nosed crimper}

The length of the flat portion was varied to give four crimper designs (Table 2), which were then compared for the same process conditions as for the round-nosed crimper design. The optimum crimper design was characterized by the maximum pullout force achieved with minimum thinning on the tube/casing wall in the crimped region [8]. The optimum crimper design was determined by plotting the pullout force for two coefficients of friction with the percentage thinning at two crimper alignments, $h=0.381$ and $0 \mathrm{~mm}$ (Fig. 2). However, only the results at an alignment of $h=0.381 \mathrm{~mm}$ (0.015 in.) are discussed in this section.

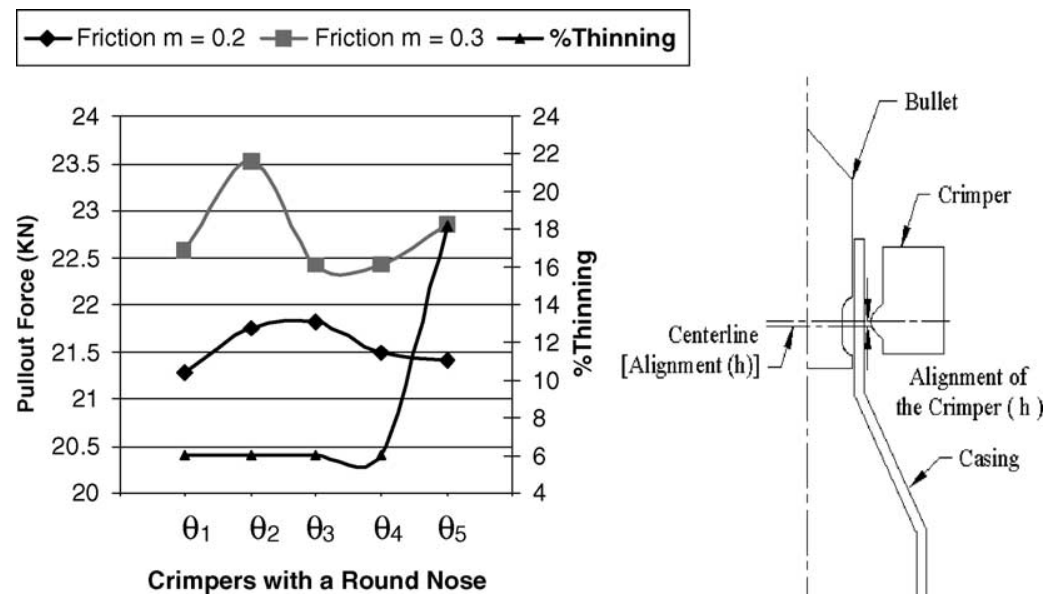

Fig. 10. Variation of the pullout force and percent wall thinning for various round-nosed crimper designs $(h=0.381 \mathrm{~mm}$ and tool stroke $=0.953 \mathrm{~mm})$. 


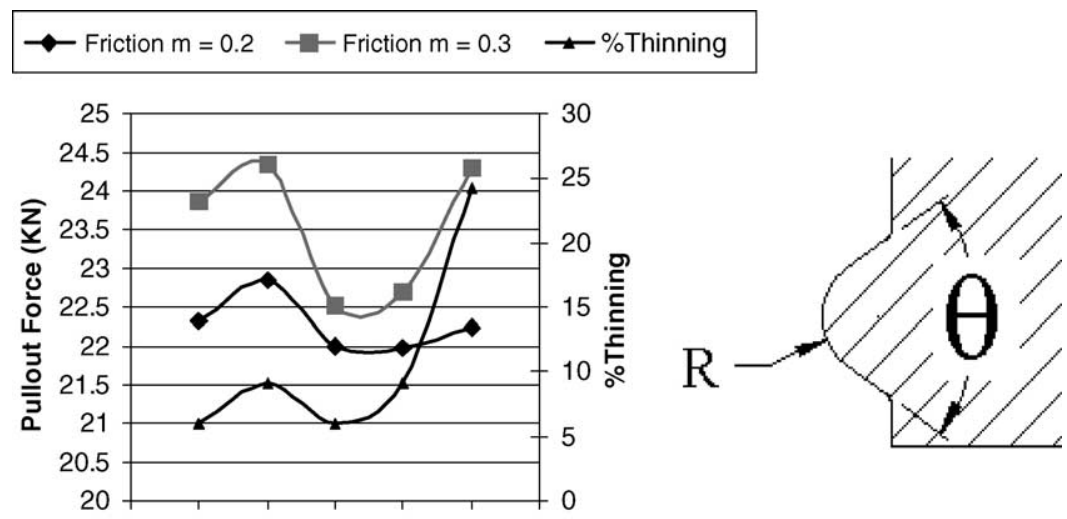

$\theta_{1} \quad \theta_{2} \quad \theta_{3} \quad \theta_{4} \quad \theta_{5}$

\section{Crimpers with a Round Nose}

Fig. 11. Variation of the pullout force and percent wall thinning for various round-nosed crimper designs $(h=0.381 \mathrm{~mm}$ and tool stroke $=1.016 \mathrm{~mm})$.

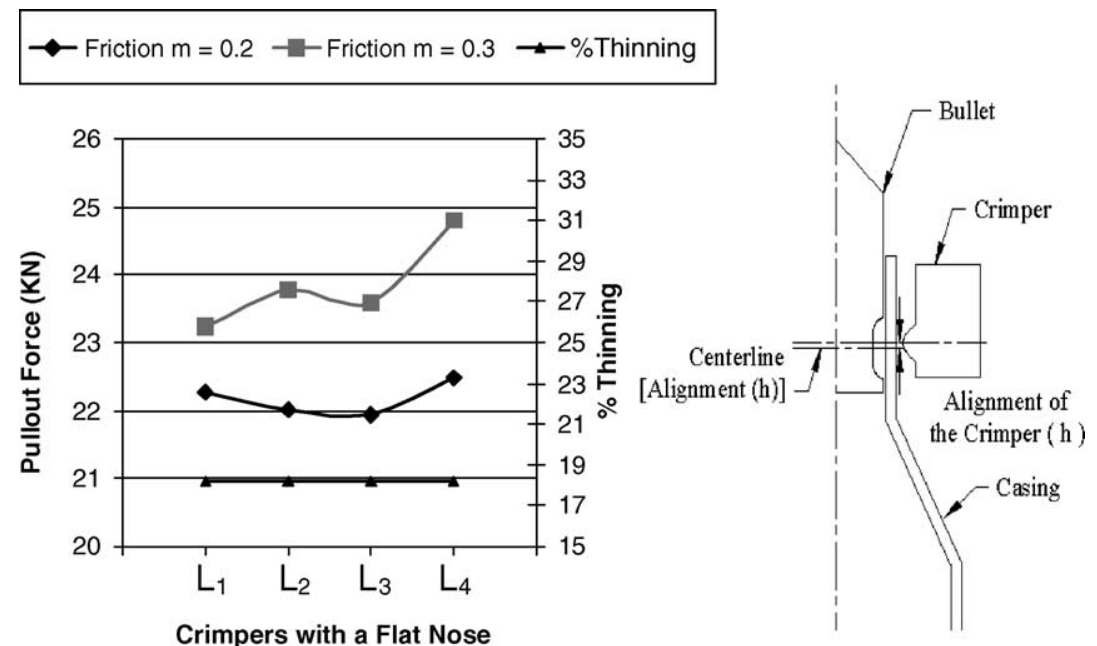

Fig. 12. Variation of the pullout force and percent wall thinning for various flat-nosed crimper designs $(h=0.381 \mathrm{~mm}$ and tool stroke $=0.953 \mathrm{~mm})$.

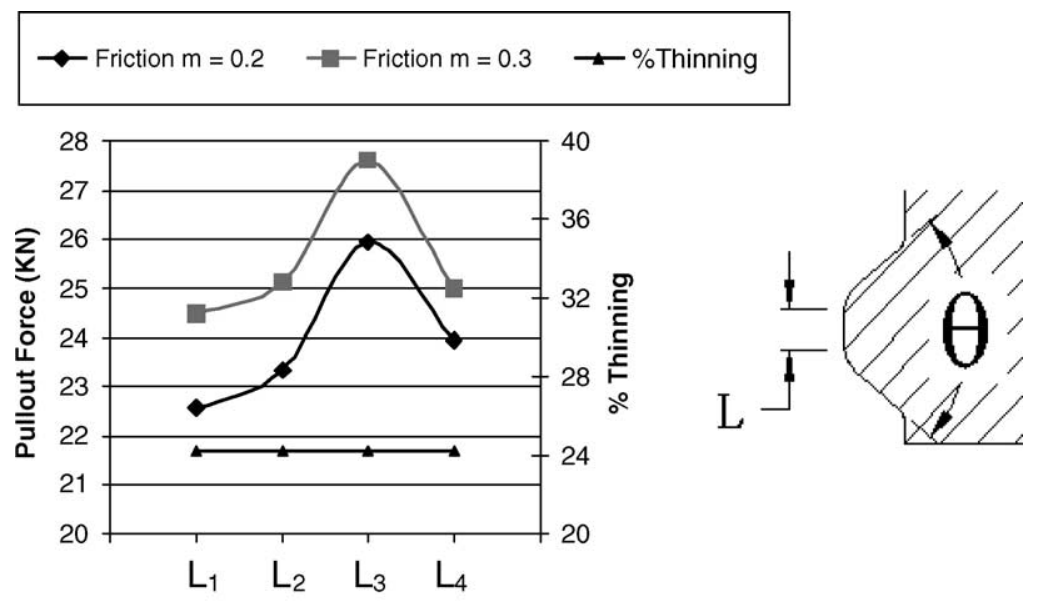

Crimpers with a Flat Nose

Fig. 13. Variation of the pullout force and percent wall thinning for various flat-nosed crimper designs $(h=0.381 \mathrm{~mm}$ and tool stroke $=1.016 \mathrm{~mm})$. 
When the tool stroke was $0.953 \mathrm{~mm}$ (0.038 in.), all the designs considered had the same thinning distribution at the crimped region. The thickness of the tube/casing was reduced by $18.18 \%$ (Fig. 12). The crimper design with a flat nose of $L_{4}$ in. was found to be optimum for both the coefficients of friction. For the coefficient of friction of 0.3 , the pullout force achieved with this design was considerably greater than that achieved with the other crimpers.

The crimper with a flat nose of $L_{3}$ in. was optimum for both the coefficients of friction for a tool stroke of $1.016 \mathrm{~mm}$ (0.04 in.) (Fig. 13). The simulation results showed a uniform increase in the pullout force for each crimper when the friction was increased to $\mu=0.3$. All the crimpers had the same thinning of $24.24 \%$ for this tool stroke.

\section{Summary and conclusions}

The crimping operation investigated in this study can be used for assembling tubular components without the use of additional joining elements. The mechanical crimping operation of a bullet was considered as a case study. Parametric studies were conducted with the aid of FEM to study the effect of various process and geometrical parameters on the crimp quality.

The material properties of the tube/casing were determined from the hardness distribution measured in the crimped region. The flow stress data thus obtained was used as an input for the simulations to evaluate the crimper alignment and geometry for different process conditions.

The major conclusions drawn from this study are:

1. The average optimum value of the crimper alignment is $0.254 \mathrm{~mm}(0.01 \mathrm{in}$.) above the centerline of the groove in the rod (bullet) for a tool stroke of $1.016 \mathrm{~mm}$ (0.04 in.).

2. For a stroke of $0.953 \mathrm{~mm}(0.038 \mathrm{in}$.), the optimum value of the crimper alignment ranges between the centerline and $0.381 \mathrm{~mm}(0.015 \mathrm{in}$.) above the centerline. This is true under the assumed interface coefficients of friction used in the simulations.

3. For geometry I (round-nosed crimpers), at the alignment of $h=0.381 \mathrm{~mm}$ above the centerline of the groove in the rod/bullet, the crimper design with crimp head angle $\theta_{2}$ was found to be optimum. However, at this alignment, for a tool stroke of $1.016 \mathrm{~mm}$, the designs with a crimp head angle of $\theta_{1}$ and $\theta_{3}$ were also possible choices for the optimization of the crimping process.
4. For geometry II (flat-nosed crimpers), at the alignment of $0.381 \mathrm{~mm}$, the crimper with a flat nose of $L_{4}$ in. was found to be optimum at a tool stroke of $0.9525 \mathrm{~mm}$ for both the coefficients of friction. For a tool stroke of $1.016 \mathrm{~mm}$, the design with a flat nose of $L_{3}$ in. gave the optimum results for both the coefficients of friction.

5. It is evident from the results that the effect of coefficient of friction used in the FE simulations of the pullout tests was significant. The friction conditions could affect the selection of the optimum design to a large extent. Thus, the lubrication conditions at the rod-tube and crimper-tube interfaces are very critical for optimizing the mechanical crimping process.

6. It was thus concluded that a parametric study of the process and geometrical parameters could successfully determine the optimum design for crimping tubular components.

\section{Acknowledgements}

The authors wish to thank the Alliant Ammunition and Powder Company, Radford Army Ammunition Plant, VA, USA for funding this study.

\section{References}

[1] J.P. Varis, The suitability of round clinching tools for high strength structural steel, Thin Walled Struct. 40 (2002) 225-238.

[2] A. Bansal, A. Schubert, M.V. Balakrishnan, M. Kumosa, Finiteelement analysis of substation composite insulators, Composite Sci. Technol. 55 (1995) 375-389.

[3] S. Jayaraman, G.T. Hahn, W.C. Oliver, C.A. Rubin, P.C. Bastias, Determination of monotonic stress-strain curve of hard materials from ultra-low-load indentation tests, Int. J. Solid Struct. 35 (1998) 364382.

[4] D. Tabor, The Hardness of Metals, Clarendon Press, Oxford, 1951.

[5] H.D. Chandler, J.-N. Gortzen, Kinetics of tensile deformation in a precipitation-hardened aluminum alloy, Mater. Sci. Eng. A 188 (1994) 97-102.

[6] H. Cho, S. Saxena, Stress analysis and evaluation of a bullet crimping process, Progress Report I, Report no. ERC/NSM-00-48, 2000.

[7] M. Shirgaokar, G. Ngaile, H. Cho, T. Altan, Stress analysis and evaluation of a bullet crimping process, Progress Report II, Report no. ERC/NSM-00-48-B, 2001.

[8] M. Shirgaokar, G. Ngaile, H. Cho, T. Altan, Stress analysis and evaluation of a bullet crimping process, Progress Report III, Report no. ERC/NSM-00-48-C, 2001. 